\title{
The Effect of the Near Earth Micrometeoroid Environment on a Highly Reflective Mirror Surface
}

\author{
(DASA-TU-101307) TEE EFEFCI CF TEE NEAR \\ EARTH UICBCAETECECID EAVIECBLEAT CA A HIGELY \\ $N 88-2 \subseteq 833$ \\ ELFLECIIVE LIEECE SUREACE (AASA) $40 \mathrm{p}$

$\begin{array}{lll}\text { CSCL 22B } & & \text { Unclas } \\ & \text { G3/15 } & 0161113\end{array}$

Michael J. Mirtich, Herman Mark, and William R. Kerslake

Lewis Research Center

Cleveland, Ohio

Presented at the

26th Aerospace Sciences Meeting sponsored by the American Institute of Aeronautics and Astronautics Reno, Nevada, January 11-14, 1988

\section{Nusn}


THE EFFECT OF THE NEAR EARTH MICROMETEOROID ENVIRONMENT

ON A HIGHLY REFLECTIVE MIRROR SURFACE

by

Michael J. Mirtich, Herman Mark, and William R. Kerslake National Aeronautics and Space Administration

Lewls Research Center

Cleveland, Ohio 44135

\section{ABSTRACT}

A resurgence of interest in placing large solar concentrator/solar dynamic systems in space for power generation has brought up again a concern for maintaining the integrity of the optical properties of highly specular reflecting surfaces in the near-earth space environment. One of the environmental hazards of concern and needing evaluation is the micrometeoroid environment. It has been shown that highly reflective polished metals and thin film coatings degrade when exposed to simulated micrometeoroids in the laboratory. At NASA Lewis Research Center, a shock tube was used to simulate the phenomenon of micrometeorold impact by accelerating micron size particles to hypervelocities. Any changes in the optical properties of surfaces exposed to this impact were then evaluated. The degradation of optical properties of polished metals and thin metallic films after exposure to simulated micrometeoroids was determined as a function of impacting kinetic energy/area of the particles. A calibrated sensor, $2000 \mathrm{~A} \mathrm{Al/stainless} \mathrm{steel,} \mathrm{was}$ developed to not only detect the micrometeoroid environment, but also to evaluate the degradation of the optical properties of thin aluminum films in space. This sensor was flown on OSO III and SERT II, satellites that were launched in 1967 and 1970 respectively. No changes in the optical properties of the highiy reflective surface were measured during 11 years in space. These results are in agreement with the 1987 micrometeoroid flux model presented in 
this paper. The results, as determined by the accuracy of the sensor, indicate that a highly reflective surface should lose less than 1 percent of its specular reflectance in near-earth orbit during 11 years.

NOMENCLATURE

$E_{c r} \quad$ cratering energy density, ergs/cc

$\varepsilon_{\text {th }} \quad$ total hemispheric emittance

e exposure, $\sum_{i} \frac{1}{2} m_{p i} v_{i}^{2}$, joules

$I_{H R} \quad$ intensity from blackbody cavity

I BB spectral energy distribution of $420 \mathrm{~K}$ (756 R) blackbody

$K$ defined in Eq. (2)

$M_{p}$ mass of impacting particle

$T_{b}$ body temperature

$T_{1,2}$ disk temperature

$V_{p} \quad$ particle velocity

$\alpha_{\text {sn }}$ normal solar absorptance

$\lambda$ wavelength of radiation, microns

$\bar{\rho} \quad$ average reflectance

$\bar{\rho}_{h-a} \quad h e m i s p h e r i c$ angular reflectance

$\bar{\rho}_{h-h}$ hemispheric-hemispheric reflectance

- Stefan-Boltzmann constant, $1.713 \times 10^{-9} \mathrm{Btu} /(\mathrm{hr})\left(f \mathrm{t}^{2}\right)\left(\mathrm{R}^{4}\right)$

$\phi \quad$ intensity of incident radiation

$\theta_{s} \quad$ sun angle

\section{Subscripts:}

a after exposure to $\varepsilon$

$i$ initial value

L laboratory conditions

$\mathrm{SP}_{1}$ space conditions 1 (see Appendix A)

$\infty \quad$ infinite exposure to particle impaction 


\section{INTRODUCTION}

A resurgence of interest in placing large solar concentrator solar dynamic systems in space for power generation has renewed interest in maintaining the integrity of the optical properties of highly specular reflecting surfaces in the near-earth space environment. One of the environmental hazards of concern needing evaluation is the micrometeoroid environment. It has been shown that highly reflective polished metals and thin film coatings degrade when exposed to simulated micrometeoroids. 1 At NASA Lewis Research Center, a shock tube was used to simulate the phenomenon of micrometeorold impact by accelerating micron size particles to hypervelocities. The optical properties of surfaces exposed to this impact were then evaluated using a Hohlraum reflectometer and a space environment facility. Thus, the degradation of the optical properties of polished metals and thin metallic films after exposure to simulated micrometeoroids was determined as a function of Impacting kinetic energy per area of the particles. Next, the abscissa (kinetic energy of the impacting particles per area) needed to be correlated with real time in space, and the effect of the micrometeorold environment on surfaces, calibrated on the ground, would be known. A calibrated sensor $2000 \AA$ Al/stainless steel was developed at NASA Lewis not only to detect the micrometeorold environment, but also to evaluate the degradation of the optical properties of a thin aluminum film in space. This sensor was flown on the OSO III and SERT II Satellites that were launched in 1967 and 1970 respectively. Data was obtained for as long as 11 years.

When the sensor was placed on these satellites, there was a lack of resolution in the measured flux of micrometeoroids near the earth (from 0.02 to several earth radif).2,3 (Note: Ref. 2 contains 48 papers on the micrometeorold environment.) This is evident in Fig. 1, where the micrometeoroid flux model of $1963^{3}$ is plotted from the direct measurements of 
interplanetary dust as recorded by various sensors on board a variety of satellites. This is a cumulative micrometeorold flux, (a sensor capable of measuring a $10^{-10} \mathrm{gm}$ particle counts all particles $10^{-10} \mathrm{gm}$ or greater) which seems to indicate that there are few or no micrometeorold particles smaller than $10^{-12}$ or $10^{-13}$ gms. For larger size meteorold particles, either photographically or optically visible $\left(10^{-5} \mathrm{gms}\right)$, efforts to measure the flux have succeeded in obtaining a satisfactory picture of the situation, at least from the engineering and even, perhaps, from the scientific point of view. However, for the fluxes of smaller particles that may exist in near-earth space, these flight experiments produced seemingly bellevable data which differed by 4 to 5 orders of magnitude. 2,3 This unsatisfactory situation existed for many reasons. Some of the most important reasons were probably connected with the extremely difficult conditions under which flight measurements were made, coupled with the further difficulty of transmitting them over long distances. The proper interpretation of results in comparison with ground calibrations made under conditions very different from those in space also contributes to the existence of great uncertainty.

The list of transducers used for measuring the flux of particles in the range of interest $\left(10^{-8}\right.$ to $\left.10^{-14} \mathrm{gm}\right)$ is almost endless.2,3 Microphone sounding boards with crystal pickups, thin opaque films painted on a transparent substrate, photoelectric pickups, penetrable gas pressure containers, and penetrable capacitors which discharge, are among many that were used. One difficulty with all of these detectors is the problem of separation of spurious signals from those actually caused by particle impact. Each of the transducers mentioned above has a number of possible sources of spurious signals. Consequently, measurements may include such an abundance of spurious signals that the results may be meaningless. Another problem with some transducers is that a hit may not give a signal. One example is a 
capacitor which does not discharge when penetrated by a particle. Similarly, particles which do not penetrate a penetration sensor cannot give a signal. In this case, the results are low and therefore meaningless. It is clear that some experiments are not valid if the flux differs by four to five orders of magnitude. 3 (See Fig. I for a $10^{-10}$ gm mass particle.)

Although all the detectors mentioned involve measurement of a physical phenomenon connected with an impact, none of these were phenomena connected with the possible engineering problem arising from impact at meteoric speeds with particles in this size range. However, the problem here is not one of penetration but rather one of erosion of surface optical properties. Reference 1 describes ground studies of micrometeorold impact and its effect on the optical properties of polished metal surfaces.

The thermal behavior of polished metal surfaces exposed to a simulated micrometeoroid flux and then exposed to a simulated space environment is presented in Ref. 4. These two studies show that relatively large changes in surface optical properties (emittance and solar absorptance) can be affected by erosion caused by simulated micrometeorold exposure. It follows, therefore, that measurements of erosion of suface optlcal properties in a flight experiment might be an excellent way not only of determining the rate of meteoroid flux in the $10^{-8}$ to $10^{-12} \mathrm{gm}$ size range but also of determining the erosive effects of this flux on surface optical properties, which is the engineering problem in question.

Surfaces in space and their optical properties can also be degraded by other features of the environment as well as by micrometeoroid erosion. Atomic oxygen, ultraviolet radiation, and proton and electron bombardment also rapidiy degrade many surfaces.5,6,7 Thus a transducer surface had to be chosen whose optical properties would be affected only by micrometeoroid erosion and by nothing else in the environment. 4,6 polished metal surfaces seemed a perfect 
choice. Not only are they relatively impervious to radiation damage but their surface properties are rapidly degraded by erosive micrometeoroid bombardment. However problems that can arise from their use as transducers are of a different nature. Due to their extremely low absorptance and emittance, polished metal surfaces are ideally suited for the detection of small amounts of surface damage, but, these very low valued optical properties, can cause difficulties in properly isolating samples of these materials from the effects of energy exchange with the orbiting vehicle.

This problem was resolved in ground studies simulating exposure to micrometeoroid erosion and the effect of such erosion on orbital temperature histories. 1,7,8 It was now possible to run a ground-flight experiment involving methods of measurements based on the 1963 micrometeoroid flux model which could determine the erosive micrometeoroid flux in orbit as well as its effect on critical surfaces. Results of these space experiments (ground micrometeoroid simulation and sensor calibration using a large solar-spaceenvironment-simulation chamber) and conclusions regarding the (1987) micrometeoroid and debris flux models are presented in this paper.

Ground Calibration

As a result of a program at NASA Lewis in the 1960's in which polished metal surfaces were exposed to impaction by high-speed, micron-size particles in the laboratory, a quantitative relation between exposure energy in joules and the degradation of the surface optical properties was found. 1 It became apparent that a flight experiment could be used to monitor surface optical properties, i.e., reflectance, to determine exposure to micrometeoroid flux. It was determined by Mark et al. 4 that reflectance measurements in flight without a reflectometer are possible and can be made with thermal measurements only. In Ref. 4, a simulated micrometeoroid exposure-temperature calibration was made in ground studies on several polished metal and thin film metal 
surfaces. Some background information on micrometeorold simulation and the method of micrometeoroid exposure-temperature callbration are presented in this section.

\section{Simulation of Micrometeorold Exposure}

In spite of the fact that, the maximum attainable speed to which particles could be accelerated intact in ground simulation tests were only a fraction of the speeds of micrometeorold particles in earth orbit, it was belleved that the phenomenon of hypervelocity impaction with micrometeorolds could be simulated best by impaction with particles at attainable speeds. In order to obtain a calibration of micrometeoroid exposure against equilibrium temperature of a thermally isolated disc under space conditions, a means of characterizing exposure both on the ground and in space was needed. Laboratory exposure quantities and change in surface property (reflectance, for instance) due to exposure are known for laboratory simulation of micrometerolds. However, in space a change in surface property could have been caused in a number of ways, and thus, not having a unique tie to the environment that caused it, fails to characterize this environment as well as the exposure itself. Therefore, the actual physical quantity to use for measuring the exposure is in question. Since a number of earlier experimental and theoretical investigations have indicated that the volume of craters formed in targets as a result of impaction with high-speed projectiles is proportionate to the kinetic energy of the projectiles, the sum of the kinetic energies of the particles striking the surface up to any time was chosen as the physical quantity characterizing the exposure. The analysis that follows is presented in Refs. 1 and 9 and provides a useful relation connecting the surface reflectance with the exposure characterized by the kinetic energy of the impacting particles. From Ref. 1 , the expression for reflectance $\bar{p}_{a}$ of a metal surface of area $A_{0}$ exposed to Impaction by particles having a total kinetic energy $\varepsilon$ in joules is 


$$
\bar{\rho}_{2}=\bar{\rho}_{1}\left[1-\left(1-\frac{\rho_{\infty}}{\rho_{1}}\right)\left(1-e^{-k \varepsilon}\right)\right]
$$

where

$$
K=\left(\frac{2}{A_{0}}\right)\left(\frac{3 \pi^{1 / 2}}{4 E_{c r}}\right)^{2 / 3}\left(m_{p} v_{p}^{2}\right)^{-1 / 3}
$$

Equations (1) and (2) allow an analytical extrapolation from the measured total energy required for a given laboratory-caused surface optical property change, to the total energy required in space for the same surface optical property change. This extrapolation requires evaluating $K$ for space and can be done if the kinetic energy of the particle in space causing most of the surface damage can be estimated reasonably (see Appendix A).

The experimental procedure for producing the laboratory damage to the surfaces is described in detall but will be discussed briefly in the following paragraphs.

Polished surfaces of soft aluminum, stainless steel, and stainless steel coated with $1900 \mathrm{~A}$ of aluminum were bombarded by clouds of SiC particles having an average dlameter of $6 \mu \mathrm{m}$ and a speed of $2.6 \mathrm{~km} / \mathrm{sec}(8500 \mathrm{fps})$. The particles were accelerated by the aerodynamic drag of the short duration flows in a shock tube, and the resultant kinetic energies

$$
\varepsilon=\sum_{1}^{N} \frac{1}{2} M_{p i} v_{p i}^{2}
$$

were obtained from strip-film camera measurements for particle speed, and microbalance collection measurements to determine the total number of particles striking a given area. 1 The measurement of speed and number of particles striking a plate were quite accurately reproducible, and the laboratory exposure energies were measured and are presented in joules. In each series 
(for each target material) the disks, $4.45 \mathrm{~cm}^{2}$, were exposed nominally to 0 , $1,2,4$, and $6 \mathrm{~J}\left(0,0.22,0.44,0.89\right.$, and $\left.1.35 \mathrm{~J} / \mathrm{cm}^{2}\right)$. This range of exposures represents changes in the reflectance of a single disc from its original value near 1.0 to about 0.5 .

Thus, there is the possibility of quantitatively exposing surfaces in the laboratory to impaction by high-speed particles of known energy per unit area and measuring the damage by means of a change of reflectance, and then to predict (Eqs. 1 and 2 ) the equivalent space exposure in energy per unit area required to produce the same surface damage. Having the exposure-surface damage relation and the surface damage-equflibrium temperature relation obtained in the simulated space environment (described in a later section), allows the design of a space experiment in which the simple monitoring of temperature of a disc in space determines not only surface damage but also the actual micrometeoroid exposure causing the damage as a function of time. This follows, of course, only if it is assumed that micrometeoroid exposure is causing the surface damage. It also is necessary to assume that normal impingement is sufficlent to simulate impingement from all directions. This is shown to be so and is discussed in Ref. 10 .

Determination of Surface Optical Properties

The discs used in this study, chosen for their good reflective properties, were made of stainless steel, aluminum, and a stainless-steel substrate with a vapor-deposited coating of aluminum, $1900 \mathrm{~A}$ thick. This coating is sufficiently thick for the surface to exhibit the optical properties of aluminum as long as the coating remains undamaged.

The discs were chosen $2.38 \mathrm{~cm}(15 / 16 \mathrm{in.})$ in dlameter and $0.046 \mathrm{~m}$ $(1 / 64 \mathrm{in.})$ to $0.16 \mathrm{~cm}(1 / 16 \mathrm{in}$.$) thick, essentially because there are$ appropriate dimensions for a sample in the heated-cavity spectrometer system for making reflectance measurements. In this system, a Perkin-Elmer $13 \mathrm{U}$ 
spectrometer compares, in a given wavelength band, radiation from a blackbody cavity at about $600^{\circ} \mathrm{C}$ to the total radiation reflected from a water-cooled sample in the same wavelength band. This technique works weil in the infrared region, but is not satisfactory at shorter wavelengths because of insufficient radiation from the heated cavity below a wavelength of about $1 \mu \mathrm{m}$. The intensity ratios obtained ( $I$ refl/IHR) are plotted as a function of wavelength and are presented for $1900 \mathrm{~A} \mathrm{Al}$ on stainless steel in Fig. 2 both before and after exposure to impaction with approximately $0.22 \mathrm{~J} / \mathrm{cm}^{2}$ of $6 \mu \mathrm{m} \mathrm{diameter} \mathrm{SiC}$ particles traveling at $2.6 \mathrm{~km} / \mathrm{sec}$ ( $8500 \mathrm{fps})$. The average values of these spectral data are presented also. The average reflectance is defined here as the single value that will reflect the same amount of energy arriving from a $420 \mathrm{~K}(756 \mathrm{R})$ blackbody source as does the sample; that is, the average reflectance $p_{2}$ is given by

$$
\bar{\rho}_{\mathrm{a}}=\frac{\int_{\lambda_{1}}^{\lambda_{2}} \rho_{H-A}(\lambda) I_{B B}(\lambda) d \lambda}{\int_{\lambda_{1}}^{\lambda_{2}} I_{B B}(\lambda) d \lambda}
$$

where

$$
\rho_{H-A}=\frac{I_{\text {REFL }}}{I_{H R}}, \lambda_{1},=1.5 \mu \mathrm{m}, \lambda_{2}=15.5 \mu \mathrm{m}
$$

The normal solar absorptance was determined from measurements made in the space environment simulator during transient heating of the exposed discs mounted in a simulated space vehicle. The total hemispheric emittance of the discs was obtained during transient cooling. Comparisons were made later between equilibrium temperatures calculated from the values of thermal optical properties obtained by these transient experiments and the actual equilibrium temperatures attained the discs in a solar simulator. 4 Infrared reflectances 
are also compared with thermally obtained disc emittances. The space chamber thermal experiment 4 will be briefly outlined later in this paper.

\section{Simulated Exposure and Surface Damage}

Reflectances for all the discs were obtained both before and after exposure, and spectral reflectance data of the type presented in fig. 2 were calculated from Eq. (4) to obtain average reflectance values weighted for the energy distribution corresponding to a $420 \mathrm{~K}(756 \mathrm{R})$ blackbody. In Fig. 3 all the average reflectance ratios for stainless steel, aluminum, and aluminum on stainless-steel, plotted against the total energy of the impacting particles. For an equuivalent reduction in reflectance in space, we also have presented the required space exposure on two additional abscissas. (See Appendix A.) The first is for a space particle of $3 \times 10^{-11} \mathrm{gm}$ (a mass of one-tenth of the laboratory particle) and a speed of $10.3 \mathrm{~km} / \mathrm{sec}$ ( $34000 \mathrm{ft} / \mathrm{sec}$ ) (compared with $2.6 \mathrm{~km} / \mathrm{sec}(8500 \mathrm{ft} / \mathrm{sec})$ for the laboratory speed). The second extra abscissa is also for a $3 \times 10^{-11} \mathrm{gm}$ particle but at $26 \mathrm{~km} / \mathrm{sec}(85000 \mathrm{ft} / \mathrm{sec})$. In the first case, an exposure of $\varepsilon S P_{1}=1.17 \varepsilon_{L}$ is required. In the second case, $\varepsilon S P_{2}=2.15 \varepsilon_{L}$ is the required exposure. This increase in exposure for space conditions to obtain equivalent damage is due to the negative one-third exponential dependency on the single particle kinetic energy of the $k$ in Eqs. (1) and (2). Thus, as the single particle kinetic energy increases, $K$ decreases (Eq. (2)), and the surface damage at a given total energy of exposure is reduced, (i.e., the reflectances do not fall as rapidly with total exposure).

The data in Fig. 3 indicate that the reduction in the infrared reflectance ratio of aluminum is somewhat greater at any exposure than that of stainless steel. The reflectance of both, however, falls to less than 60 percent of the original value after only $7.5 \mathrm{~J}\left(1.65 \mathrm{~J} / \mathrm{cm}^{2}\right)$ of laboratory exposure.

The reflectance ratio of the disc of stainless steel coated with $1900 \mathrm{~A}$ of aluminum follows the reflectance ratio of aluminum until the exposures are 
increased to cause a 60 percent reduction in reflectance ratio after which the increased aluminum-coated stainless steel approaches that of the substrate stainless steel as the aluminum coating is being eroded away. To obtain these curves, the values for $\rho_{\infty}$, the reflectances of the samples at infinite exposure, were determined in Ref. 11. The value for aluminum obtained at $5.6 \mathrm{~J} / \mathrm{cm}^{2}$ exposure is 0.3055 . For stainless steel, $\rho_{\infty}=0.350$ (obtained at $6.7 \mathrm{~J} / \mathrm{cm}^{2}$ exposure). In addition to pointing out the reduction in exposed surface reflectivity, Fig. 3 also suggests that the aluminum-coated disc should degrade like aluminum at first; then after some exposure (as the coating is removed), resemble the degradation rate of the substrate stainless steel. Since the reflectance ratio degradation rate for the aluminum coated surface has slowed to that of the stainless steel, the effect of the aluminum coating on stainless steel is to keep the absolute reflectance up throughout the experiment, longer than that of aluminum alone, and hence for a longer time than might be expected in space.

Space Simulation Chamber

A space-environment-simulation facility was used to determine the equilibrium temperature of the surfaces described in this paper. 4 In the working section of the inner "space" chamber, which was $6 \mathrm{ft}$ in diameter and approximately $10 \mathrm{ft}$ high, four characteristics of the space environment were reproduced simultaneously and as accurately as possible. The first was the low pressure of gases in space, estimated to be about $10^{-14} \mathrm{~mm} \mathrm{Hg}$.

This low pressure was obtained by keeping the entire chamber wall at liquid helium temperatures by jacketing. The liquid helium cooled jacket provided nearly perfect absorption capability of the space background for gases. The inner space chamber walls jacketing also produced the extremely low background temperature of space (about $4 \mathrm{~K}$ ), thus removing any superfluous radiation source. The most important radiant energy source in space is, of 
course, the sun. In this facility, the radiation arriving from the sun, at earth distance from the sun (but outside earth atmosphere), was provided by a carbon arc lamp at the proper intensity, uniformity, and collimation angle. The resulting spectral energy distribution approximated that of the sun over the wavelength range from $3500 \AA$ to about $2.5 \mu \mathrm{m}$. Details concerning the monitoring and maintenance of these conditions are presented in Refs. 4 and 12 .

Space-Chamber-Temperature Experiment

Five identical $2.38 \mathrm{~cm}(15 / 16$ in.) diameter polished discs were selected for a given material, and each disc was then subjected to a given amount of laboratory exposure. The exposure was increased from disc to disc. Each series of discs of a given material was then mounted on a simulated spacecraft that had been designed to minimize heat transfer between the spacecraft and the mounted discs (Fig. 4). This was accomplished by mounting the discs on nonconducting plastic stems and shielding the back of the discs with highly reflecting cups, thus allowing a heat balance for the discs only involving received and emitted radiation from the front exposed side of the disc and a minimum loss from the unexposed side $\left(3 \times 10^{-12} \mathrm{Btu} /(\mathrm{hr})\left(R^{4}\right)\right]$. The simulated vehicle was mounted in the space-environment tank so that the front faces of the discs received direct solar radiation from a direction normal to their surfaces. The front surfaces of the discs were also exposed to the cold sink of space over nearly the entire $2 \pi$ solid angle (except for the sun). Thus, the discs could arrive at the equilibrium temperature based on the heat balance between the normal energy (solar radiation) absorbed and the total hemispheric energy emitted by the front face (plus the energy loss to the supporting spacecraft structure). The equilibrium temperature for each disc was measured by a copper-constantan thermocouple embedded in the disc one-half radius out from the mounting pin at the center. The equilibrium temperature of the disc was detemined by taking measurements of temperature while approaching 
equilibrium conditions from above and below the equilibrium temperature.

During the experiment, radiation intensity was monitored by six silicon solar cells previously calibrated against a Schwarz total radiation intensity meter. The resulting variation in the equilibrium temperatures for all the discs is the result of reproducible changes in surface optical properties caused by calibrated exposure to high-speed, micron-size particle impaction.

Transient temperatures were measured similarly during heating and cooling of the discs for the purpose of determining $\alpha_{S N}$ and $\varepsilon_{T H}$ by an essentially independent experiment (independent from the equilibrium experiment).

Results of Space-Chamber-Temperature Experiment

The major results of the temperature-equilibrium experiment are presented in Fig. 5 and Tables 1 and 2. The "history" of the equilibrium temperature for discs of three different materials mounted on a simulated space vehicle and "flown" in a simulated space environment at 1.25 solar constant can be found in Fig. 5. These equilibrium temperatures are shown as they vary with exposure to the simulated micrometeoroid environment, the exposure being expressed in joules per square centimeter of energy of the impacting hypervelocity particles on the $2.38 \mathrm{~cm}$ diameter discs. Perhaps the most important feature of these curves is that, in spite of the large exposure to impacting particles, the resulting change in optical properties measured in the laboratory, and the efforts made to isolate the disc thermally from its support, the total variation in equilibrium temperature of the discs is small but measurable. For the aluminum disc, the measured change in equilibrium temperature is approximately $21 \mathrm{~K}$ or about 5 percent in absolute temperature level. For stainless steel, the temperature is almost constant, varying only about 0.1 percent in absolute temperature level. The largest variation occurred with the aluminum-coated stainless-steel disc, which rose $50 \mathrm{~K}$ due to the exposure, or about 12 percent in absolute temperature level. The 
equilibrium temperature variations as measured for the discs and presented in Fig. 5 also are presented in Table 1 for comparison with the equilibrium temperature calculated for the discs by using values for $\alpha_{S N}$ and $\varepsilon_{T H}$ determined from the two auxiliary nonsteady experiments (the first sun-on, the other sun-off).

The check obtained between measured and calculated values is quite good. Also presented in Table 1 are the values of $\alpha_{5 n}$ and $\varepsilon_{\text {th }}$ measured in the thermal transient experiment for each of the discs as the laboratory exposure is increased. It is clearly shown that both $\alpha_{s n}$ and $\varepsilon_{\text {th }}$ increase due to the exposure. Both stainless steel and aluminum on stainless steel are leveling off to about the same temperature. This was expected, as the aluminum coating is worn from the stainless-steel substrate. The all-aluminum disc wears most rapidly and exhibits the strongest rise in $\varepsilon_{t h}$, but not the highest $\alpha_{s n}$; hence it approaches the lowest equilibrium temperature in Fig. 5 .

For the information presented in Table 2 , the $\varepsilon_{\text {th }}$ of Table 1 was used to calculate a reflectance ( $i . e ., \rho=1-\varepsilon_{T H}$ ) solely for comparison with $\bar{\rho}_{a}$, the average reflectance of the discs measured by the spectrometer method. These two "reflectances" can be compared, because $\bar{\rho}_{a}$ is equal approximately to $\rho_{H-A}$, for the materials in this experiment, and $\rho_{H-H}$ can be taken equal to $\left(1-\varepsilon_{t h}\right)$ at the same temperature. 4 The comparisons of these two quantities for the discs are amazingly close considering the difference in the paths traveled to obtain them. Whether or not such a comparison is strictly correct, the optical or thermal changes in surface property are certainly varying in a very similar manner with simulated exposure to micrometeoroid environment.

This similarity in the variation of reflectance with exposure as measured by $e^{i t h e r}$ method suggested the possibility of making reflectance measurements in space without a reflectometer, and also using these reflectance measurements to determine micrometeoroid flux. 
This could be done by calibrating the change in temperature of a disc in a space-environment-simulation chamber with the measured (elsewhere) optical change of the surface caused by calibrated exposure of the disc to simulated micrometeoroid flux. Telemetering the temperature of the disc from a space experiment then would give not only the change in reflectivity of the disc but also, from correlation with the ground experiment, the micrometeoroid flux causing this reflectivity change. The surface chosen for space-flight experiments, because of its initial fast rise in equilibrium temperature and large changes initially in $\alpha_{s n}$ and $\varepsilon_{\text {th }}$ when exposed to simulated micrometeoroids, (see Fig. 4 and Table I) was the $1900 \mathrm{~A} \mathrm{Al/stainless} \mathrm{steel}$ disc. Discs with $2000 \mathrm{~A}$ of Al/S.S. Were placed thermally isolated from the spacecraft on OSO III, and SERT II. The following section describes both of these space experiments and discusses the results.

SPACE EXPERIMENTS

SERT II - REX

The SERT II (Solar Electric Rocket Test II) spacecraft was launched in 1970 as a 6-month test bed for the operation of an ion thruster in space.13 A secondary experiment on the spacecraft, called REX (Reflector Erosion experiment) was designed to measure micrometeoroid degradation of a highly reflective aluminum disc. This section presents the first published REX results. It covers space-obtained data from the first 9 months of the mission in 1970 and also data obtained during an extended mission through 1981, a total period of 11 years, 3 months in space. 4,13

\section{REX Description}

Figure 6 shows an artist's drawing of the REX apparatus. Figure $6(2)$ is the mounting body used to control the thermal environment of the disc in the back hemisphere. Two discs, $2.38 \mathrm{~cm}$ in diameter and $0.013 \mathrm{~cm}$ thick, with a 
2000 A coating of aluminum vapor deposited on the disc front face, were used in this flight experiment. Figure $6(b)$ shows details of mounting the disc to the body. The mounting structure was designed to control heat transfer between the disc and body to a value between 8.3 to $16.6 \times 10^{-18} \mathrm{~J} / \mathrm{sec}-\mathrm{K}^{4}$. Cool-down data taken on the flight apparatus before launch determined the actual value to be $13.3 \times 10^{-18} \mathrm{~J} / \mathrm{sec}-\mathrm{K}^{4}\left(4.8 \times 10^{-12} \mathrm{Btu} / \mathrm{hr}-\mathrm{R}^{4}\right)$.

Thermistor sensors mounted on the two discs (disc No. 1 is the upper one, and disc No. 2 the lower) and on the front (semi-side) plate of the body provided temperature data. The thermistor data were transferred via the connector plug (shown on the cup side) to the spacecraft telemetry system, which digitized it and radio-linked it to an earth receiving station. Each digital bit was equivalent to $1 K$, or the temperature step between measurable values. The thermistor sensors and telemetry system were calibrated before launch. The sensitivity of flight REX temperature data was $\pm 0.5 \mathrm{~K}$. The sensor stability specification was $\pm 0.5 \mathrm{~K}$ for 6 months and is as good as the drift of the resistance of a high-quality resistor. The telemetry-thermistor ground calibration gave the absolute temperature to $\pm 1 K$; and repeated in-space telemetry calibrations showed no discernable change in the telemetry system through 1981. The design range of the disc sensor was 325 to $380 \mathrm{~K}$ ( $\mathrm{T}_{1}$ and $T_{2}$ ) and the body sensor range was 266 to $349 \mathrm{~K}$ (Tb). REX temperature sensors were scanned and recorded every 4 min by the telemetry system.

The REX body was mounted on the end deck of the SERT II spacecraft as shown in Fig. 7. A protective cover (removed before launch) was placed over the REX discs in Fig. 7. The disc front side (2000 A aluminum) was in a plane perpendicular to the deck and had a nearly-clear hemispherical view of space and earth. The plane of the disc was in the spacecraft orbit plane. The launch time, direction and altitude were picked to be sun-synchronous; thus, 
the orbit plane was nominally perpendicular to the sun direction $\left(\theta_{S}=0^{\circ}\right)$ and the REX disc surface was sun-facing. (The exact sun direction will be shown in the figures to follow.)

There was no direct line-of-sight between any active spacecraft component and the front disc surface. The mercury ion thruster exhaust consisted of 90 percent high velocity $(30,000 \mathrm{~m} / \mathrm{sec})$ well collimated ions, 9 percent neutral mercury atoms and 1 percent low velocity $(1000 \mathrm{~m} / \mathrm{sec})$ charge exchange ions. For any neutral exhaust atom to reach the disc front surface, would require an improbable collision with a space particle downstream of the thruster exhaust, where the mean free path is greater than $1000 \mathrm{~m}$. Because of the warm $(340 \mathrm{~K})$ disc temperature, any occasional mercury atom or ion arriving at the disc would re-evaporate. The ion thruster grids were made of molybdenum and there was some ion sputtering of grid molybdenum. 14 If the molybdenumsputtered atoms became charged, some would be attracted back to the spacecraft and, because of its low vapor pressure, would not re-evaporate. The most probable landing area would be on the deck or ion thrustor sides and and not on the REX discs. Temperature sensors located on the deck, ion thrustor side, and other thermal-emissive-sensitive places around the spacecraft, shown in Fig. 8, indicated no unexpected change in temperature during the mission. Perhaps the most sensitive sensor of all, the main solar arrays, showed lessthan-predicted space degradation; thus, indications were that no molybdenum or any other condensible contaminant deposited on the REX discs.

\section{REX Design Background}

The REX experiment was designed to study the space temperature history of a highly reflective aluminum surface. The REX experiment was made $\alpha_{s n \text {-change }}$ sensitive with small effects due to $\varepsilon_{\text {th }}$ changes. By using aluminum with an $a_{s n}$ of 0.111 and an $\varepsilon_{\text {th }}$ of 0.017 , a heat transfer (disc-to-body) of 
$13.3 \times 10^{-18} \mathrm{~J} / \mathrm{sec}-\mathrm{K}^{4}$, and the micrometeoroid flux model of $1963^{2,3}$ presented in Fig. 1, a REX disc temperature rise of 20 to $30 \mathrm{~K}$ was expected after 1 year in space. For example, the REX disc with a $1 \mathrm{~J}\left(0.22 \mathrm{~J} / \mathrm{cm}^{2}\right)$ exposure of micrometeoroid flux would experience a $37 \mathrm{~K}$ temperature increase. This was the sum of a $42 K$ rise due to $\alpha_{s n}$ increase and a $5 K$ drop due to $\varepsilon_{\text {th }}$ increase.

\section{SERT II Spacecraft History}

The SERT II spacecraft was launched in February 1970. Its major objective was the testing of an ion thruster in space for 6 months. A polar launch orbit was necessary to give a sun-synchronous orbit which would provide steady solar array power to operate the ion thrusters. The $1000 \mathrm{~km}$ orbit altitude was the highest available from the rocket launch vehicle. This was high enough to have a long decay orbit life (500 years) and have a low density space background for ion thruster testing.

Due to a triaxial earth, the orbit did not remain inertially fixed, but precessed slowly with a 20 -year period. After 2 years, the orbit was no longer sun synchronous (causing the spacecraft to enter the earth's shadow) and the sun angle on the orbit plane (and solar array) changed from nearly normal to $31^{\circ}$ off normal (at first entering earth's shadow). It then continued to $90^{\circ}$ in 1975 and $180^{\circ}$ in 1980 .

To continue experiments past 1971, it was necessary to turn the solar array (and spacecraft) to face the sun to obtain enough power to operate experiments. To keep facing the sun, the spacecraft was spin-stabilized in 1973. (From 1970 to 1972 , the spacecraft was gravity-gradient stabilized as shown in Fig. 8.) Then in late 1976, the original spin direction was changed to obtain more sun on the solar arrays, and a proper orientation attitude, for operation in 1979, when the orbit became sun-synchronous again. In late 1981 the orbit precession caused periods of earth shadowing of the spacecraft, and 
spacecraft operations were terminated with the spacecraft in working order. Continuous sun light orbit will again occur in 1989.

During the periods of earth shadowing, the REX data were in non-thermal equilibrium, due not only to the shadow cooling, but also to large changes in sun angle caused by the spinning spacecraft. Therefore no REX data are plotted for these periods. The precession or wobble of the spacecraft spin axis had a period of a few days to a few weeks. During the wobble periods, changes in REX disc temperature ( 293 to $320 \mathrm{~K}$ ) were used to measure the wobble period and to calculate the sun angle on REX (and hence the main solar array). These calculations could be made because $\alpha_{s n}$ and $\varepsilon_{\text {th }}$ had not changed significantly during the mission to that time.

During the spin-wobble years of 1973 to 1977 , the REX disc was partially exposed to ram atomic oxygen. For those years there was a period of 1145 days of such exposure. The ram angle on the disc varied from $0^{\circ}$ to $18^{\circ}$ (a perpendicular or direct ram angle would be $90^{\circ}$ ). Integration of the ram angles over the 1145 days resulted in an equivalent direct ram time of only 40.1 days. Because of the altitude $(1000 \mathrm{~km})$ and length of time in the ram direction, there is a negligible probability of atomic oxygen effects on the discs.

REX Data

Figure 9 is a time plot of REX thermal data from launch (Feb. 1970) to the end of data collection (May 1981). The two disc temperatures, the body or cup temperature, and sun angle of incidence on the discs were plotted. The shaded areas were times when the spacecraft was intermittently shadowed by the earth. (See SERT II Spacecraft History Section.) All data on Fig. 9 were uncorrected. To minimize any variation due to earth view factor or earth albedo, only data taken when the spacecraft was over Fairbanks, Alaska were plotted. This location was chosen because a majority of data came from the telemetry 
receiving station there. REX data were also compared over a ground station in Australia and showed no significant difference from the Alaska data.

The disc temperatures in Fig. 9 show almost no long-term change or trend with time. There seemed to be a small trend of lower disc temperature in the year 1971. The REX body or cup temperature was also fairly constant across time. The random, small temperature changes were partly due to changes of the sun angle causing local shadowing from the nearby RFI antenna, (Fig. 7), sun rays reflecting off the aluminum spacecraft deck, or seasonal changes in earth albedo. The change in sun angle closely followed the predicted orbit precession for the launch orbit. When the sun angle was larger than $31^{\circ}$, the spacecraft passed into the earth's shadow, and no data were plotted due to non-normal thermal equilibrium. Transient thermal data were not discriminant because the 4-min data sampling rate was large compared to the REX thermal time constant. Although no data were plotted for earth shadow periods, i.e., 1972 - 1979, the REX discs were exposed to ambient micrometeoroid flux at all times. Temperature data from disc 1 were lost after 1972 when the telemetry subcommutator that processed disc 1 thermistor data stopped functioning.

\section{REX Data Discussion}

The disc temperature data of Fig. 9 can be enhanced by applying small corrections resulting from changes in REX body temperature and changes of incident solar intensity. Equation (B3) of Ref. 4 relates disc temperature ( $T_{1}$ or $T_{2}$ ) with $\alpha_{S n}, \varepsilon_{t h}$, REX body temperature, and solar intensity. A simplified form of Eq. (B3) is presented below:

$$
\left[T_{1} \text { or } T_{2}\right]^{4}=\frac{\left[\alpha_{s n}+C_{1} T_{B}^{4} / \cos \theta_{S}\right]}{\left[C_{2} \varepsilon_{t h} / \cos \theta_{S}+C_{1} / \cos \theta_{s}\right]}
$$

where $C_{1}$ and $C_{2}$ are constants. 
For constant $\alpha_{S n}$ and $\varepsilon_{\text {th }}$ Eq. (5) reduces to the form:

$$
\left[T_{1} \text { or } T_{2}\right]^{4}=C_{3} \cos \theta_{S}+C_{4} T^{4}
$$

where $C_{3}$ and $C_{4}$ are constants.

For the nominal values of $\theta_{S}=0^{\circ}$ and $T_{B}=316 \mathrm{~K}, T_{1}$ or $T_{2}$ equals $344 \mathrm{~K}$. Expected changes in $T_{1}$ or $T_{2}$ due to sun angle or body temperature changes can be calculated by using the actual instead of nominal values of $\theta_{s}=0$ and $T_{b}=316 \mathrm{~K}$. These calculated changes in $T_{1}$ or $T_{2}$ (amounting to -0.5 to $8 \mathrm{~K}$ ) were used to correct or enhance the data of Fig. 9 by normalizing $T_{1}$ or $T_{2}$ to constant values of $T_{b}$ and $\theta_{S}\left(316 \mathrm{~K}\right.$ and $\left.0^{\circ}\right)$. The corrected $T_{1}$ and $T_{2}$ data are plotted on Fig. 10.

Both the raw data (Fig. 9) and the normalized data (Fig. 10) showed the same major result. That is, there was no major change in disc temperature ( 30 to $40 \mathrm{~K}$ ) due to exposure to space micrometeoroids over a period of 11 years and 3 months. This result indicated that the micrometeoroid flux model of the $1960^{\prime} s^{3}$ was considerably higher than the real flux.

OSO II I

The $2000 \mathrm{~A} \mathrm{Al} / \mathrm{S} . \mathrm{S}$. Reflector erosion micrometeoroid detector was also part of the thermal control coatings experiment flown on OSO III corbiting Solar Observatory III). This satellite was launched into a low-earth, nearly circular equatorial orbit on March 8, 1967, and was operational for at least 5 years. The orbit altitude was about $550 \mathrm{~km}$ and was inclined $33^{\circ}$ relative to the earth's equator. The orbit period was $96 \mathrm{~min}$, with about $60 \mathrm{~min}$ of the orbit being in sunlight. The satellite was spin-stabilized with a rate of $35 \mathrm{rpm}$. This spin axis was perpendicular to the satellite-sun line. Twelve coatings, (mostly thermal control), mounted on thin discs about 1 in. $(2.54 \mathrm{~cm}$ ) in diameter, were exposed to the space environment; each coated disc was 
thermally isolated on the back side. Changes in solar absorptance $\left(\alpha_{s n}\right)$ and thermal emittance $\left(\varepsilon_{T H}\right)$ values were deduced from transient temperature measurements of the discs.

One of the results pointed out by the principal investigator, J. Millard, 5 written in 1968, was that for the $2000 \mathrm{~A} \mathrm{Al}$ on stainless steel, "No changes in $\alpha_{s n}$ or $\varepsilon_{\text {th }}$ of the 2000 A Al coating were detected in a time period of about 11 months. This result is highly significant in that it indicates effects of micrometeoroids were negligible."

Upon a request by $H$. Mark of NASA Lewis Research Center to Ames Research Center, the transmitter was turned on and data obtained on the $2000 \mathrm{~A} \mathrm{Al}$ disc after 5 years in orbit. Again, there were no changes in $\alpha_{s n}$ or $\varepsilon_{\text {th }}$ of the disc, indicating again that the effects of the micrometeoroid environment on this surface were negligible even after 5 years in an equatorial orbit. These data are shown in Fig. 11 as $\Delta \alpha_{s n}$ versus time. No change in $\alpha_{s n}$ indicates no change in the total solar reflectance, since $\bar{\rho}_{S}=1-\bar{\alpha}_{S n}$, for an opaque surface.

\section{RESULTS AND DISCUSSION OF SPACE EXPERIMENT}

Implication on Micrometeoroid and Space Debris Models and Erosion of Surface Optical Properties

As pointed out in the introduction, the placing of the micrometeroid sensor (2000 A Al/S.S.) in space was founded on the 1963 Interplanetary Dust Measurements presented in Fig. 1. From this model of the micrometeoroid environment, we expected a flux of approximately $350000 \mathrm{hits} / \mathrm{cm}^{2} /$ year which is dominated by low mass particles $\left(10^{-12}\right.$ to $\left.10^{-10} \mathrm{gm}\right)$. This translates to an energy on our sensor of approximately $1 / 3 \mathrm{~J} / \mathrm{year}\left(0.067 \mathrm{~J} / \mathrm{cm}^{2} / \mathrm{yr}\right)$ for a particle velocity of $20 \mathrm{~km} / \mathrm{sec}$. We set our sensor sensitivity for a minimum rise in temperature of $1 K$, because of this flux model. A simple calculation shows that the minimum energy we could have detected on our sensor, because of 
this sensitivity, was $0.00067 \mathrm{~J} / \mathrm{cm}^{2}$. The REX discs on SERT II experienced no rise in temperature in 11 years and no change in solar absorptance in 5 years on OSO III. This certainly implies that the energy of the impacting micrometeoroids was less than $0.003 \mathrm{~J} / 11$ years $=0.00027 \mathrm{~J} /$ year or 0.000067 $\mathrm{J} / \mathrm{cm}^{2} / \mathrm{yr}$. Assigning a velocity of $20 \mathrm{~km} / \mathrm{sec}$ to the micrometeoroids yields a flux for the $10^{-12} \mathrm{gm}$ particles of approximately $350 \mathrm{hits} / \mathrm{cm}^{2} / \mathrm{yr}$ or $10^{-1}$ hits $/ \mathrm{m}^{2} / \mathrm{sec}$, the minimum number of hits detectable by this sensor in 11 years. This data point is plotted on $\mathrm{Fig}$. 12, along with the micrometeoroid flux models of 1963 and 1987, and the 1987 space debris model presented by L. Jaffe of J.P.L. in Ref. 16. The 1987 micrometeoroid flux model presented is the same as that presented in SP-8013,17 where only micrometeoroid penetration data were used to generate the flux.

This NASA near-earth micrometeoroid model has been widely accepted, and continues to be used even though it was first published in 1969 . It is the present-day meteoroid model and is therefore called the 1987 meteoroid model in Fig. 12. This is also cited by Jaffe in an extensive review of available data on the micrometeoroid and space debris environments. Jaffe cites and reviews 30 references in recommending models of these environments for the $100 \mathrm{~kW}$ space nuclear power system, SP100.18 In this J.P.L. Internal office Memo, he discusses the studies of Kessler 19,20,21,22 (considered by many to be the number one authority on space debris); a debris model by Laurance and Brownlee 23 (based on pits on Solar Max surfaces); and meteoroid models generated by Aguero, McDonne 11, Laurance and Brownlee, Whipple and Cour-Palais. 17

The results of the SERT II or OSO III Flight Experiment are consistent with both the 1987 micrometeoroid and space debris flux models. In fact, they verify that the flux is less than or equal to the quantities observed, which 
is consistent with these models. This is why a vertical arrow is drawn down from our data point, meaning the flux was even less than our sensor could detect.

The resulting data imply that solar dynamic reflector surfaces such as the reflector surface (a highly polished metal or thin metal film deposit) tested in space should lose less than 1 percent of their specular reflectance over a period of 11 years. An extrapolation based on area damage derived from the 1987 micrometeoroid model and ground reduction in specular reflectance due to micrometeoroid similation studies indicates that such a reduction in specular reflectance should not happen within the useful lifetime of currently conceived space systems.

\section{CONCLUDING REMARKS}

A shock tube was used to accelerate micron-size particles to hypervelocities to simulate micrometeoroid impact on polished metal surfaces. An analytic expression was derived, which predicts reduction in reflectance of polished metal surfaces as a function of area damaged, that correlates with the kinetic energy of the impacting hypervelocity particles. A space simulation facility was used to calibrate a micrometeoroid sensor (2000 A Al/S.S.). It was found that this sensor, thermally isolated from the spacecraft, exhibited a rapid rise in equilibrium temperature when exposed to simulated micrometeoroid exposure. This micrometeoroid sensor was then flown on two satellites, OSO III (equitorial orbit) and SERT II(polar orbit). No changes in either equilibrium temperature or optical properties of the highly reflective surface were measured in 11 years in space. The effects of the space environment, i.e., the micrometeoroid environment on the solar reflectance were negligible. The results are in agreement with the 1987 micrometeoroid flux model presented in the paper. From the accuracy of the sensor, the results indicate that a reflector surface (a highly polished metal 
or a thin metal film deposit) should lose less than 1 percent of its specular reflectance in near-Earth orbit in 11 years. This result alone will be very useful to the design of space solar dynamic/concentrator systems. 


\section{APPENDIX A}

SPACE EXPOSURE FOR EQUAL DAMAGE

In Eq. (1) of this paper the surface reflectance after exposure to impaction is written

$$
\bar{\rho}_{\mathrm{a}}=\bar{\rho}_{\mathfrak{i}}\left[1-\left(1-\frac{\bar{\rho}_{\infty}}{\bar{\rho}_{\mathfrak{i}}}\right)\left(1-\mathrm{e}^{-k_{\varepsilon}}\right)\right]
$$

where

$$
K=\left(\frac{2}{A_{0}}\right)\left(\frac{3 \pi}{4 E_{C R}}\right)^{2 / 3} \frac{1}{\left(m_{p} v_{p}^{2}\right)^{1 / 3}}
$$

For equal damage on a given surface, that is, constant $\bar{p}_{d}$, the quantity $K$ must be held constant. If $K$ changes with single particle kinetic energy as in Eq. (A2), $\varepsilon$ must change to keep

$$
K_{L} \varepsilon_{L}=K_{S P} \varepsilon_{S P}
$$

or

$$
\varepsilon_{S P}=\left(\frac{K_{L}}{K_{S P}}\right) \varepsilon_{L}
$$

from Eq. (A2)

$$
K \sim\left(m_{p} v_{p}^{2}\right)^{-1 / 3}
$$

and $\mathrm{Eq}$. (A4) becomes

$$
\varepsilon_{S P}=\left(\frac{m_{\rho S P} V_{\rho S P}^{2}}{m_{P L} V_{P L}^{2}}\right)^{1 / 3} \varepsilon_{L}
$$

Thus, for the higher particle kinetic energies in space, the total exposure required for the same damage is increased (i.e., more hits in space are required for the same surface damage).

In the laboratory exposure, the particle mass was $3 \times 10^{-10} \mathrm{gm}$. For use in space, a good estimate of the mass of the most numerous particle may be made by finding the leveling-off point of the cumulative flux curve from Fig. 1. A 
conservative figure for the most numerous (minimum size) particle in space from these data, from the point of view of extrapolating our laboratory exposure to space, is about $3 \times 10^{-11} \mathrm{gm}$, or one-tenth of the laboratory particle mass.

Estimates for particle speed in space vary from 30000 to $200000 \mathrm{fps}$.

To calculate several examples we have taken one at 34000 fps (four times lab speed) and 85000 fps (10 times lab speed). Using Eq. (A5) we have case 1 .

Let $m_{\rho S P}=m_{\rho L} / 10$ and $v_{S P}=4 V_{P L}$. Then

$$
\begin{gathered}
\varepsilon_{S P_{1}}=\left[\left(\frac{m_{\rho S P}}{m_{\rho L}}\right)\left(\frac{V_{\rho S P}}{V_{P L}}\right)^{2}\right]^{1 / 3} \varepsilon_{L} \\
\varepsilon_{S P_{1}}=\left[\left(\frac{1}{10}\right)(4)^{2}\right]^{1 / 3} \varepsilon_{L} \quad \varepsilon_{S P_{1}}=1.17 \varepsilon_{L}
\end{gathered}
$$

In case 2 , let

$$
\begin{gathered}
m_{S P}=\frac{m_{P L}}{10} \quad v_{\rho S P}=10 V_{P L} \\
\varepsilon_{S P_{2}}=\left[\left(\frac{1}{10}\right)(10)^{2}\right]^{1 / 3} \varepsilon_{L} \quad \varepsilon_{S P_{2}}=2.15 \varepsilon_{L}
\end{gathered}
$$

28 


\section{REFERENCES}

Mirtich, M.J., Mark, H., "Feasibility of accelerating micron-size particles in shock-tube flows for hypervelocity degradation of reflective surfaces" NASA TN D-3187, Jan. 1966.

${ }^{2}$ Hawkins, G.S. (editor), "Meteor Orbits and Dust" Proceedings of a Symposium, Aug. 9-13, 1965 - NASA SP - 135, SCA Vol. II, pp. 1-411.

${ }^{3}$ Alexander, W.M., McCraken, C.W., Secretan, L. and Berg, O.E., "Review of Direct Measurements of Interplanetary Dust from Satellites and Probes," Proceedings of the Third International Space Sciences Symposium, edited by W. Priester (John Wiley and Sons, Inc., N.Y. 1963, sec. C2, paper 1, pp. $891-917$.

${ }^{4}$ Mark, H., Sommers, R.D., Mirtich, M.J., "Effect on Surface Thermal Properties of Calibrated Exposure to Micrometeoroid Environment," AIAA Journal, Vol 4, No. 10, pp. 1811-1818, Oct. 1966.

5 Millard, J.P., "Results from the Thermal Control Coatings Experiment on OSO-III," 3rd Thermophysics Conf. AIAA June 24-26, 1986, AIAA paper 68-794.

6Parsons, R.L., Gulino, D.A., "Effect of an Oxygen Plasma on Uncoated Thin Aluminum Reflective Films," NASA TM-89882, May 1987.

7Banks, B., Mirtich, M.J., Rutledge, S.K., Swec, D.M., "Ion Beam Sputter Deposited Thin Film Coatings for Protection of Spacecraft Polymers in Low Earth Orbit, NASA TM-87051, Jan. 1985.

${ }^{8}$ Summers, R.D. and Mark, H., "Effect on Nonperfect Isolation in the Temperature of Metal Surfaces on Satellites," AIAA J., Vol. 4, No. 6, pp. 1092-1095, June, 1966.

9Mark, H., Goldberg, G. and Mirtich, M.J., "Determination of Cratering Energy Densities for Metal Targets by Means of Reflectivity Measurements," AIAA J.2 965-966 (1964). 
${ }^{10}$ Summers, J.L., "Investigation of high-speed impact: Regions of impact at oblique angles," NASA TN D-94 (1959).

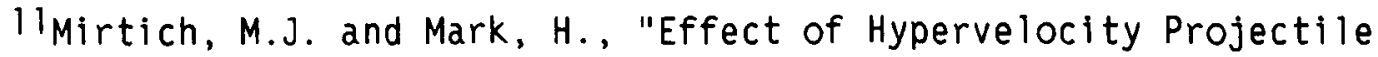
Material on the Ultimate Reflectance of Bombarded Polished Metals," NASA TM X-52981, Apri1, 1971.

12Uguccini, O.W. and Pollack, J.L., "A Carbon-arc Solar Simulator," A.S.M.E. paper 62-WA-241 (1962).

13SERT II Mission, Thrust Performance, and In-Filight Measurements, W.R. Kerslake, R.G. Goldman, and W.C. Nieberding, Journal Spacecraft and Rockets, Vol. 8, No. 3, March 1971.

14SERT II Spacecraft Thruster Restart 1974, W.R. Kerslake and R.C. Finke, Journal Spacecraft and Rockets, Vol. 12, No. 12, December 1975.

15Mirtich, M.J., Weigand, A.J., "Change in Transmittance of Fused Silica as a Means of Detecting Material Sputtered from Components in a 5-cm ion Thruster," NASA TM X-68073, May 1972.

16Jaffe, L., J.P.L.- IOM 313/09 -LJ: rap to J. Rose, "Meteoroid and Debris Environment Mode1s," June 5, 1987.

${ }^{17}$ Cour-Palais, B.G. "Meteorold Environment Model" - 1969 [Near Earth to Lunar Surface], NASA SP-8013, 1969.

18Brandhorst, H.W., Jr., Juhasz, A.J., Jones, B.I., "Alternative Power Generation Concepts for Space," NASA TM-88876, 1986.

19Kessler, D.J., "Orbital Debris Issues," in Space Debris, Asteroids and Satellite Orbits. Advances in Space Research, 5, No. 2, pp. 3-10, 1985 . 20Kessler, D., "Earth Orbital Pollution," in Beyond Spaceship Earth. Environmental Ethics and the Solar System. E.D. Hargrove, Editor Sierra Book Club, San Francisco, pp. 47-65, 1986.

21 Kessler, D.J., "Sources of Orbital Debris and the Projected Environment for Future Spacecraft," Journal of Spacecraft and Rockets, 18, 357-380 (1981). 
22Su, S.Y. and Kessler, D.J., "Contribution of Explosion and Future Collision Fragments to the Orbital Debris Environment," in Space Debris, Asteroids and Satellite Orbits. Advances in Space Research, 5, No. 2, pp. 2.3-24 (1985).

23Laurance, M.R. and Brownlee, D.E., "The Flux of Meteroids and Orbital Space Debris Striking Satellites in Low Earth Orbit," Nature, 323, pp. 136-138 (1986). 
TABLE 1. - VARIATION OF OPTICAL PROPERTIES AND EQUILIBRIUM TEMPERATURES OF METAL OISKS WITH SIMULATED MICROMETEOROID EXPOSURE

\begin{tabular}{|c|c|c|c|c|c|}
\hline \multicolumn{6}{|c|}{ Aluminum } \\
\hline $\begin{array}{l}\text { Lab exposure, } \\
\text { joules/cm² } \\
\text { asN } \\
\text { ETH } \\
T_{\text {eq }}(\mathrm{calc}),{ }^{\circ} \mathrm{K} \\
\mathrm{T}_{\text {eq }} \text { (meas), }{ }^{\circ} \mathrm{K}\end{array}$ & $\begin{array}{r}0 \\
0.230 \\
0.061 \\
405 \\
403\end{array}$ & $\begin{array}{r}0.28 \\
0.447 \\
0.184 \\
428 \\
419\end{array}$ & $\begin{array}{r}0.60 \\
0.451 \\
0.243 \\
416 \\
415\end{array}$ & $\begin{array}{r}1.26 \\
0.572 \\
0.282 \\
430 \\
424\end{array}$ & $\begin{array}{r}5.71 \\
1.02 \\
0.675 \\
431 \\
425\end{array}$ \\
\hline \multicolumn{6}{|c|}{304 Stainless steel } \\
\hline $\begin{array}{l}\text { Lab exposure, } \\
\text { joules } / \mathrm{cm}^{2} \\
\text { asN } \\
\text { eTH } \\
\text { Teq (calc), oK } \\
\text { Teq (meas), oK }\end{array}$ & $\begin{array}{r}0 \\
0.432 \\
0.112 \\
443 \\
437\end{array}$ & $\begin{array}{r}0.21 \\
0.579 \\
0.221 \\
442 \\
443\end{array}$ & $\begin{array}{r}0.48 \\
0.618 \\
0.301 \\
432 \\
438\end{array}$ & $\begin{array}{r}0.96 \\
0.691 \\
0.338 \\
436 \\
439\end{array}$ & $\begin{array}{r}1.46 \\
0.793 \\
0.366 \\
450 \\
442\end{array}$ \\
\hline \multicolumn{6}{|c|}{ Aluminum $(1900 \AA)$ on 304 stainless steel } \\
\hline $\begin{array}{l}\text { Lab exposure, } \\
\text { joules/cm² } \\
\text { asN } \\
\text { eTH } \\
\text { Teq (calc), ok } \\
\text { Teq (meas), ok }\end{array}$ & $\begin{array}{r}0 \\
0.111 \\
0.017 \\
375 \\
390\end{array}$ & $\begin{array}{r}0.24 \\
0.428 \\
0.175 \\
426 \\
428\end{array}$ & $\begin{array}{r}0.44 \\
0.475 \\
0.204 \\
429 \\
433\end{array}$ & $\begin{array}{r}1.01 \\
0.563 \\
0.245 \\
436 \\
435\end{array}$ & $\begin{array}{r}1.37 \\
0.702 \\
0.308 \\
445 \\
440\end{array}$ \\
\hline
\end{tabular}

TABLE 2. - COMPARISON OF REFLECTANCE $\bar{\rho}_{\mathrm{a}}$ WITH THE QUANTITY ( 1 - eTH)

\begin{tabular}{|c|c|c|c|c|c|}
\hline \multicolumn{6}{|c|}{ Aluminum } \\
\hline $\begin{array}{l}\text { Lab exposure, joules } / \mathrm{cm}^{2} \\
\rho_{a} \text { (for } 420 \text { oK blackbody radiation) } \\
\left(1-e_{T H}\right)\end{array}$ & $\begin{array}{r}0 \\
1.01 \\
0.94\end{array}$ & $\begin{array}{l}1.28 \\
0.80 \\
0.82\end{array}$ & $\begin{array}{l}0.60 \\
0.76 \\
0.76\end{array}$ & $\begin{array}{l}1.26 \\
0.62 \\
0.72\end{array}$ & $\begin{array}{l}5.71 \\
0.305 \\
0.325\end{array}$ \\
\hline \multicolumn{6}{|c|}{304 Stainless steel } \\
\hline $\begin{array}{l}\text { Lab exposure, joules } / \mathrm{cm}^{2} \\
\rho_{\mathrm{a}} \text { (for } 420 \text { oK blackbody radiation) } \\
\left(1-e_{T H}\right)\end{array}$ & $\begin{array}{r}0 \\
0.92 \\
0.89\end{array}$ & $\begin{array}{l}0.21 \\
0.79 \\
0.78\end{array}$ & $\begin{array}{l}0.48 \\
0.71 \\
0.70\end{array}$ & $\begin{array}{l}0.96 \\
0.66 \\
0.66\end{array}$ & $\begin{array}{l}1.46 \\
0.57 \\
0.63\end{array}$ \\
\hline \multicolumn{6}{|c|}{ Aluminum $(1900 \AA)$ on stainiess steel } \\
\hline $\begin{array}{l}\text { Lab exposure, joules } / \mathrm{cm}^{2} \\
\rho_{\text {pa (for } 420 \text { oK blackbody radiation) }} \\
\text { (1 - eTH) }\end{array}$ & $\begin{array}{r}0 \\
1.02 \\
0.98\end{array}$ & $\begin{array}{l}0.24 \\
0.81 \\
0.82\end{array}$ & $\begin{array}{l}0.44 \\
0.77 \\
0.80\end{array}$ & $\begin{array}{l}1.01 \\
0.67 \\
0.75\end{array}$ & $\begin{array}{l}1.37 \\
0.63 \\
0.69\end{array}$ \\
\hline
\end{tabular}



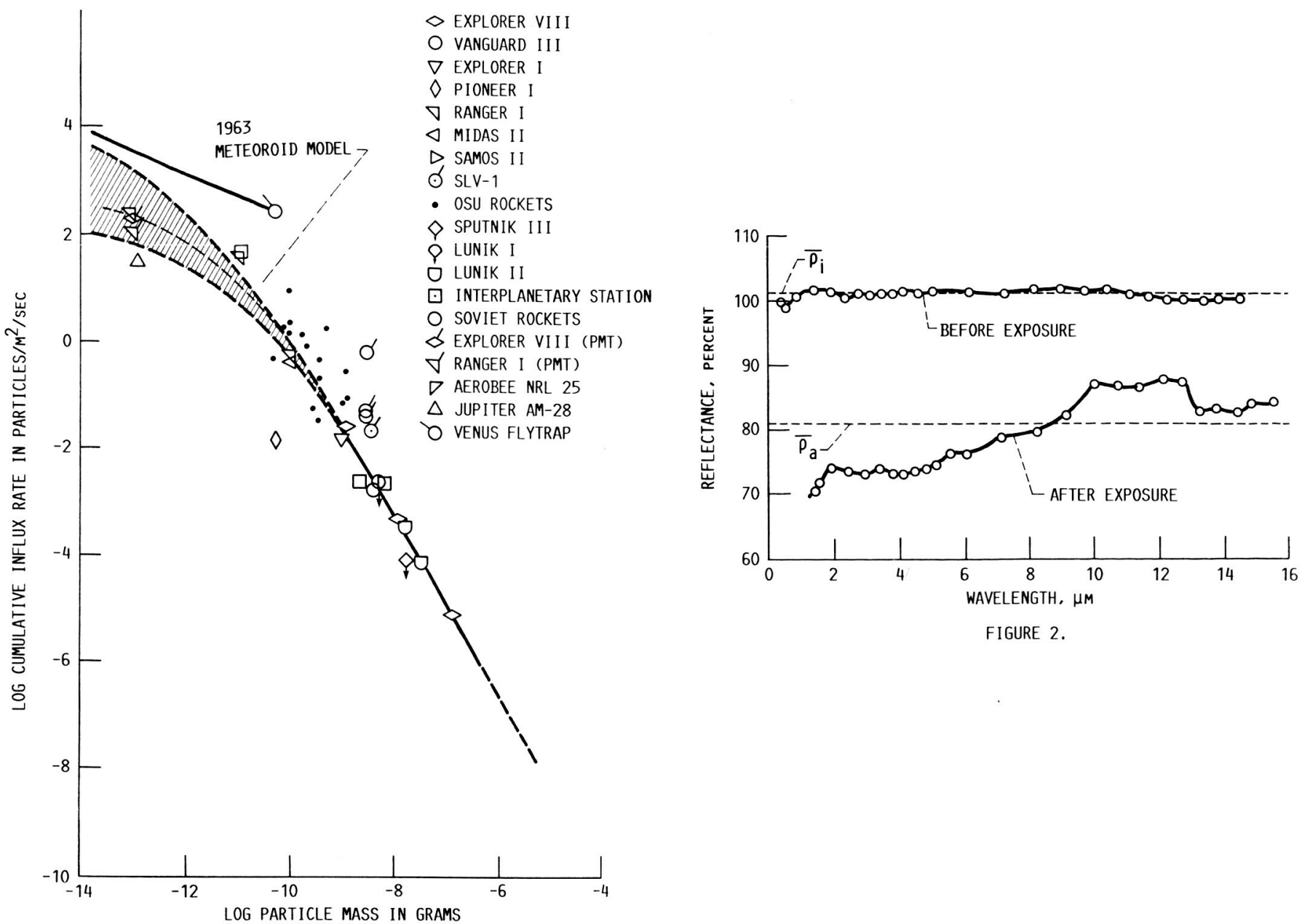

FIGURE 2.

FIGURE 1.

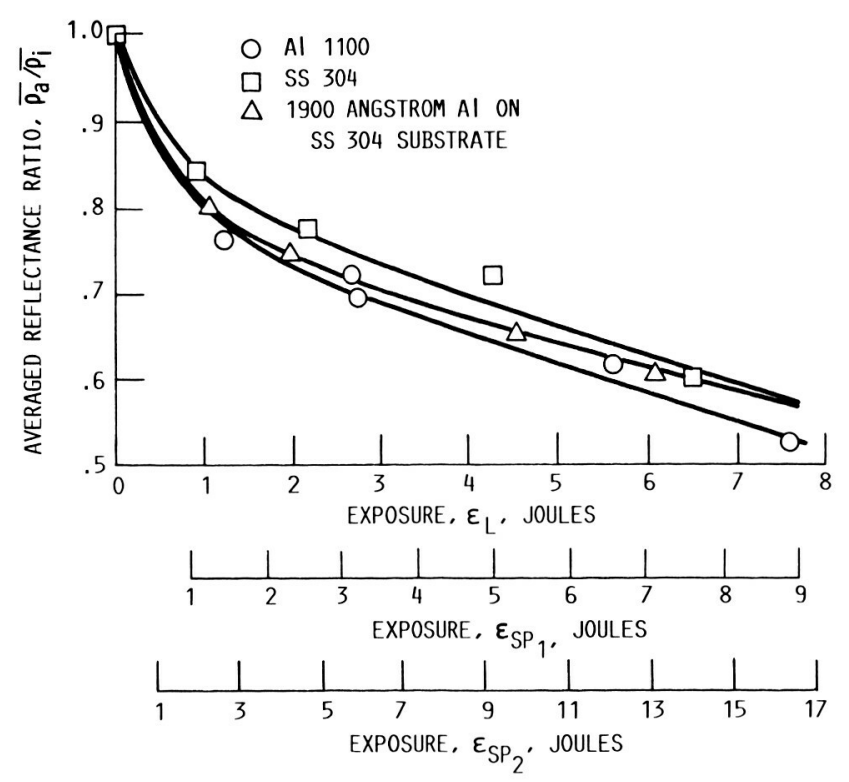

FIGURE 3. 


\section{ORIGINAL PAGE IS \\ OF POOR QUALTYY}

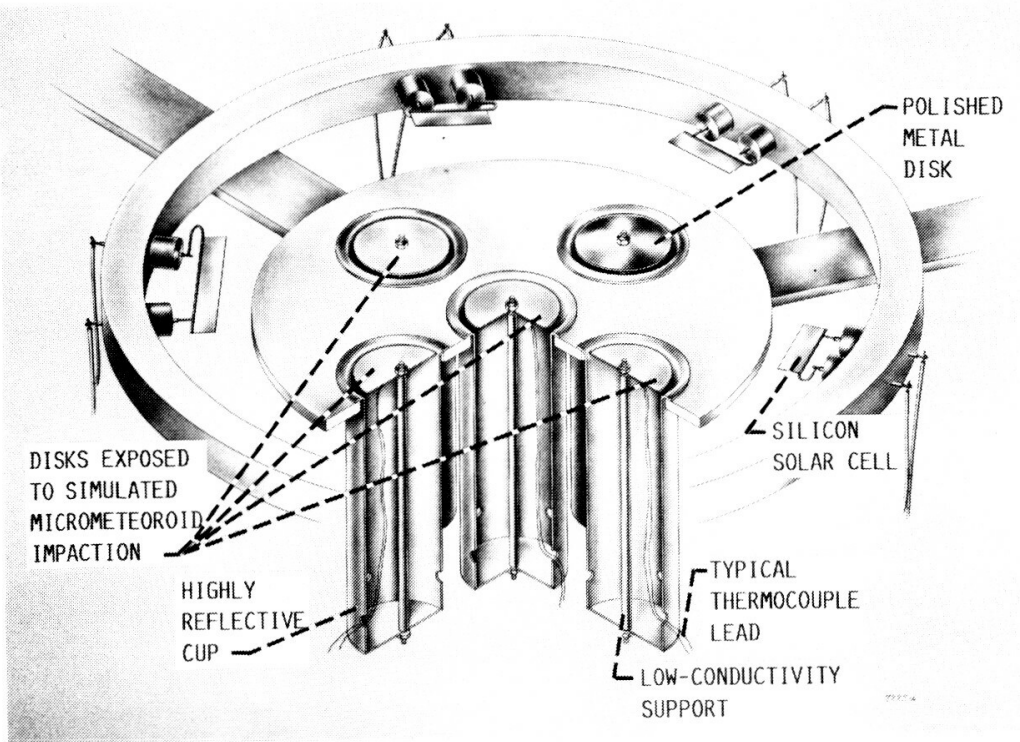

FIGURE 4.

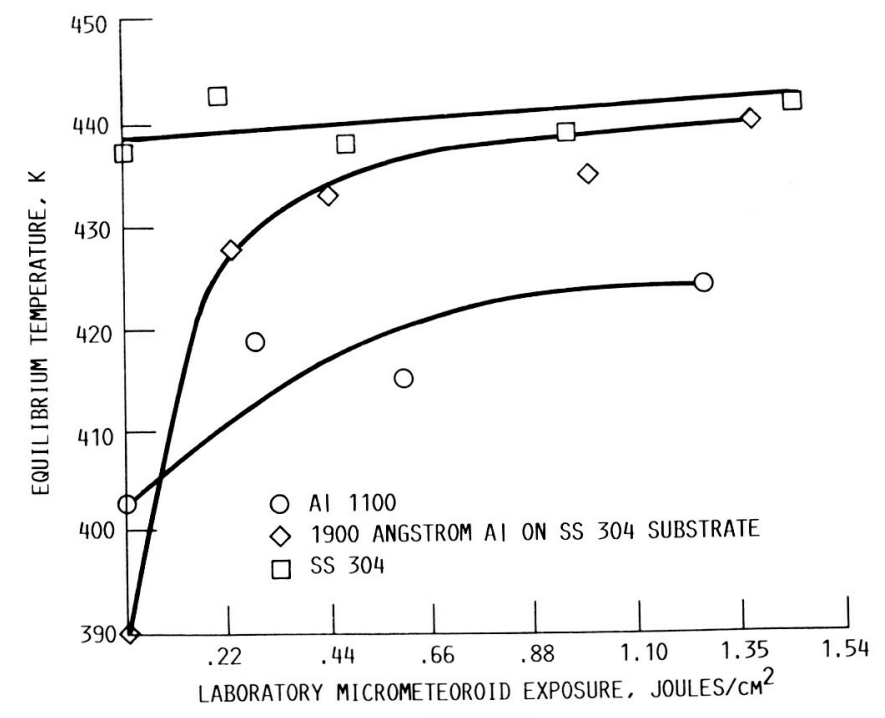

FIGURE 5. 


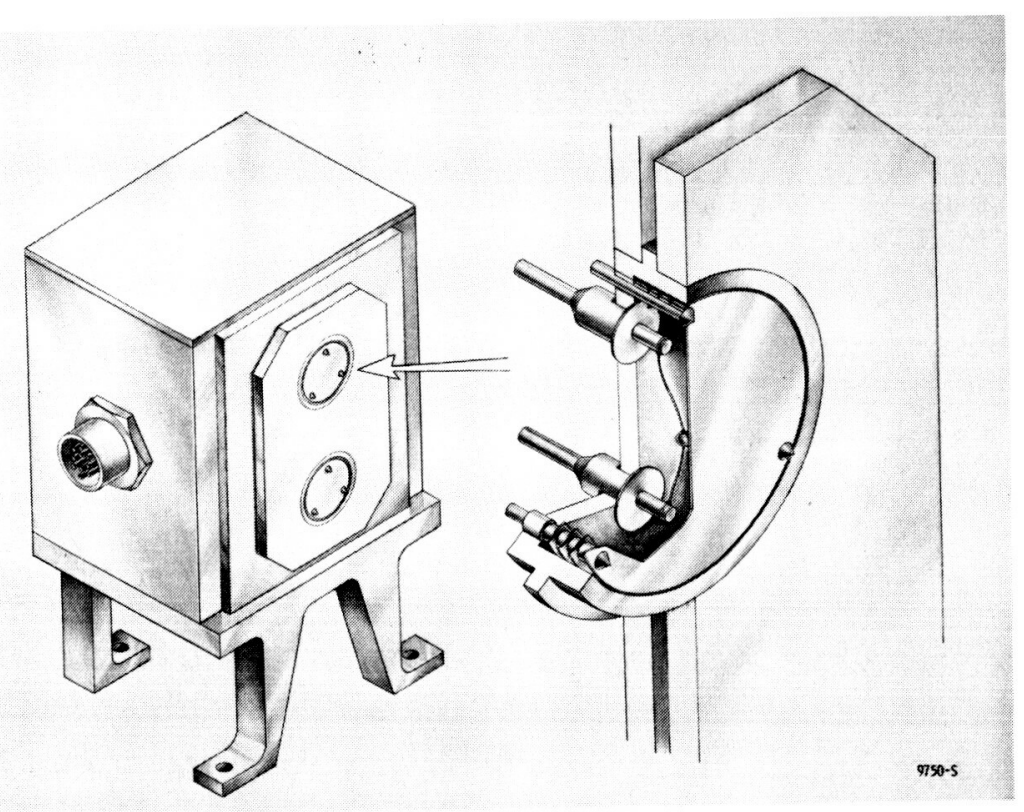

FIGURE 6.

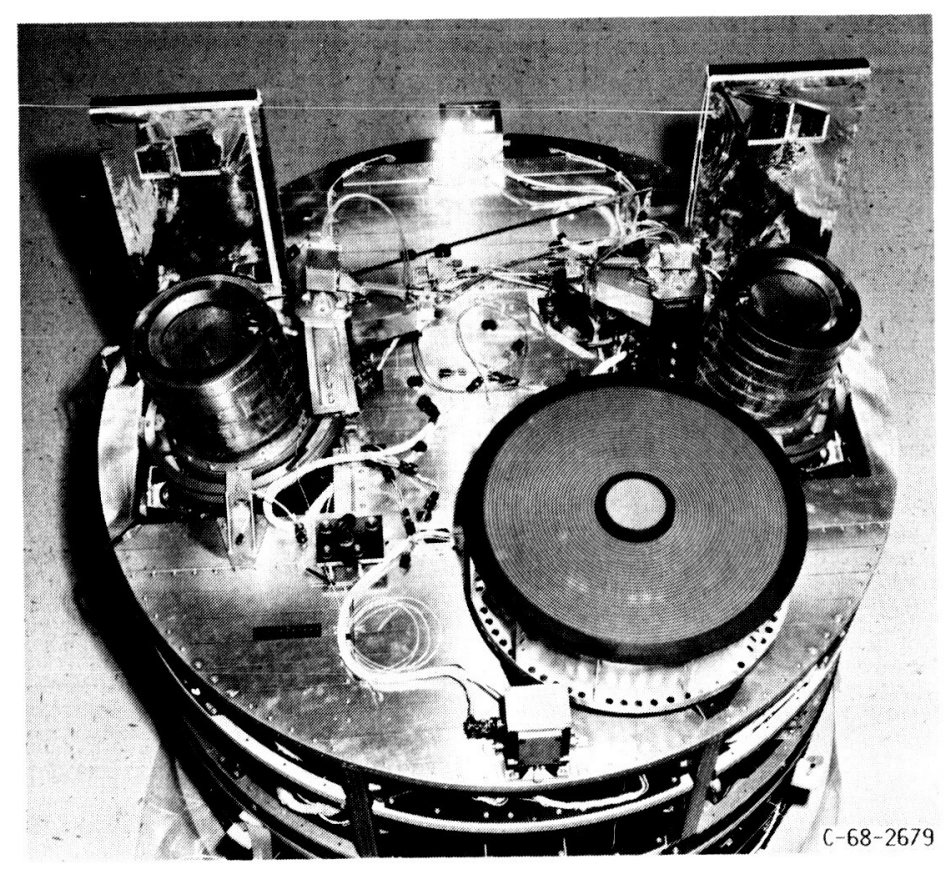

FIGURE 7. 


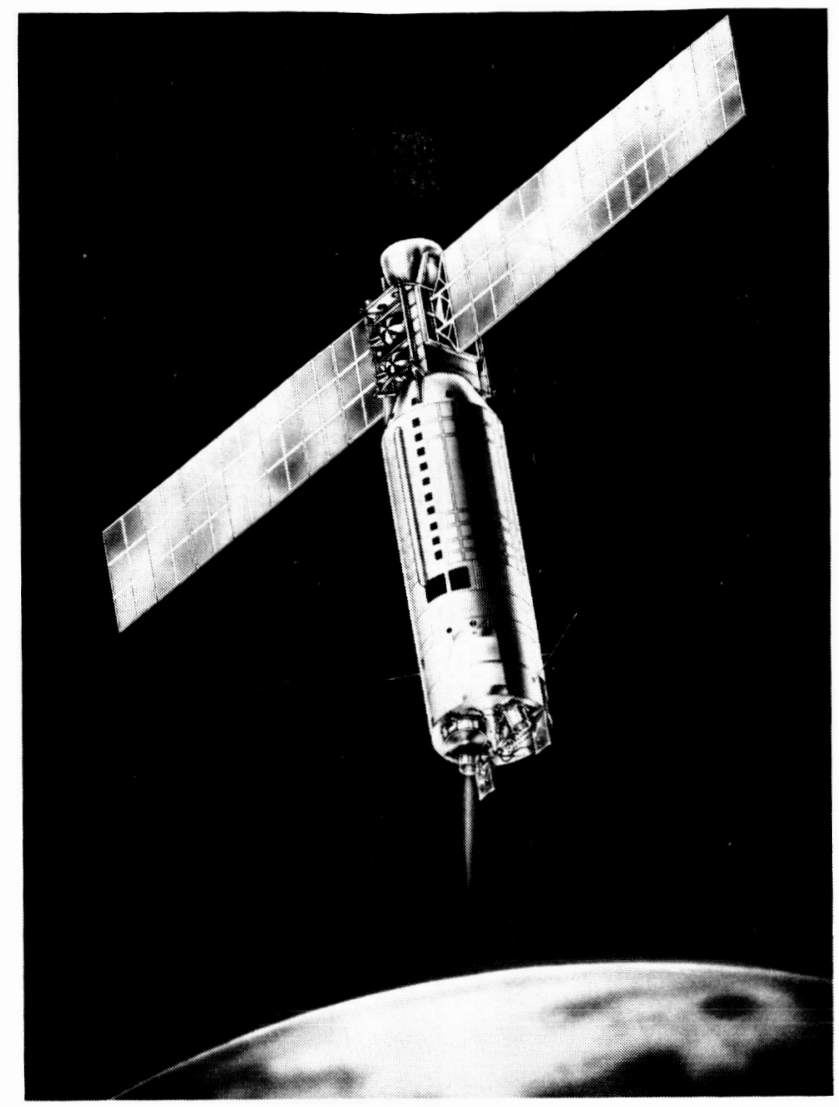

FIGURE 8.
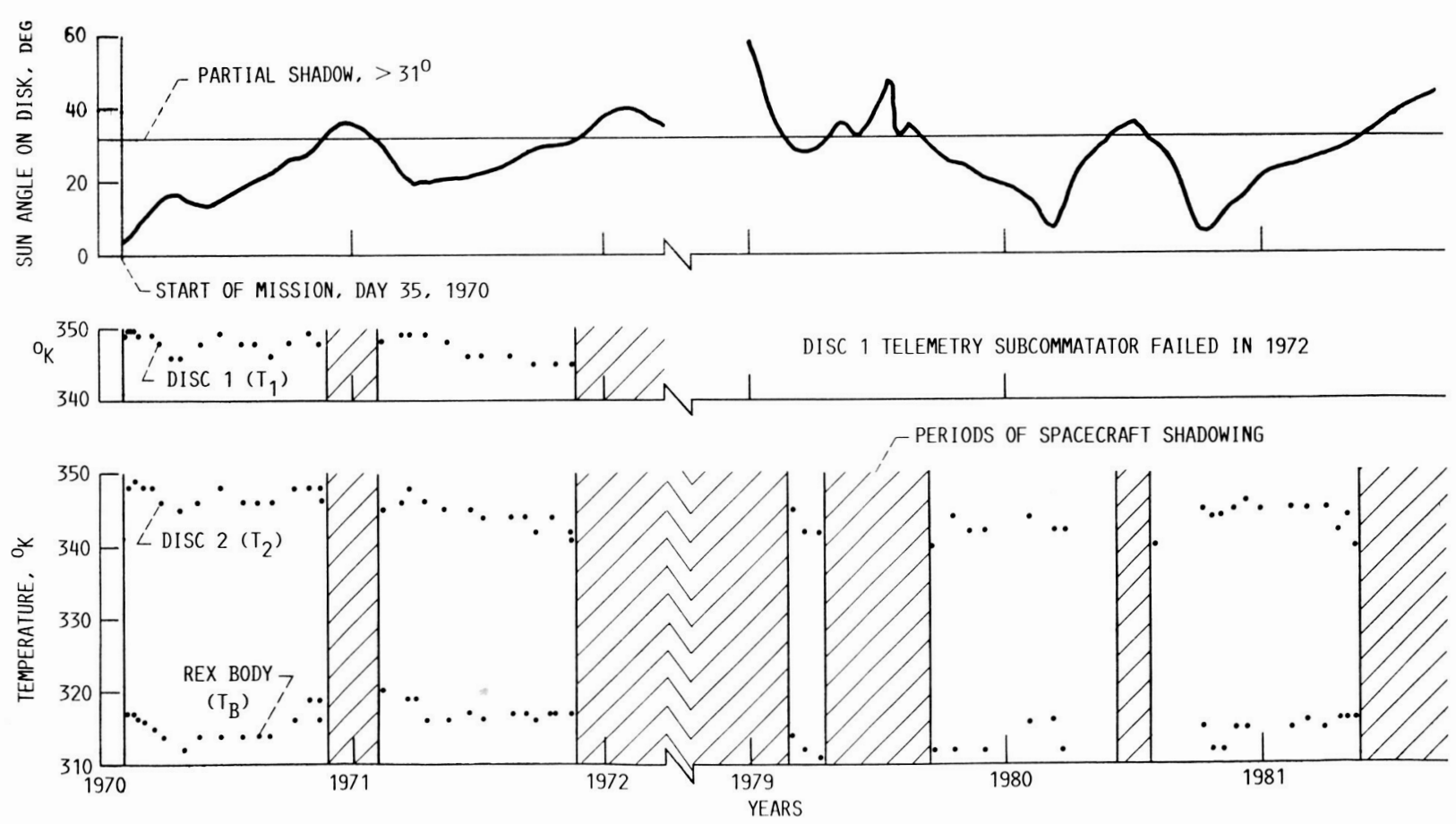

FIGURE 9. 


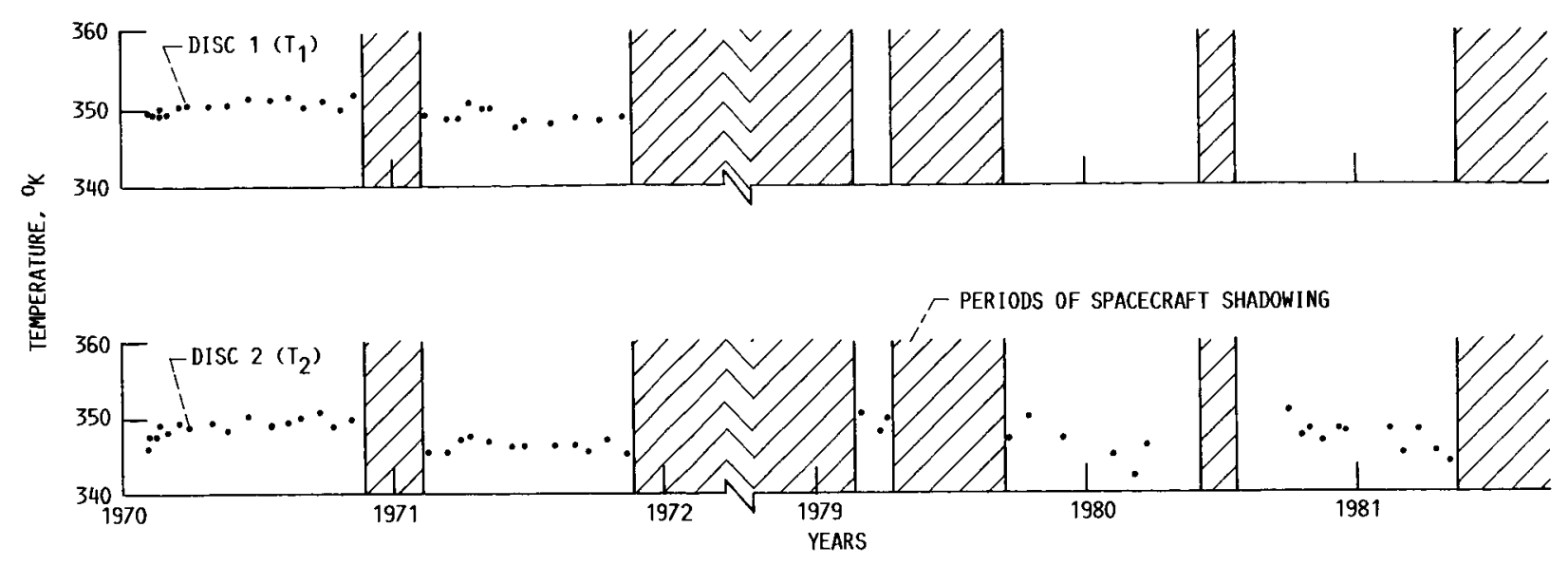

FIGURE 10.

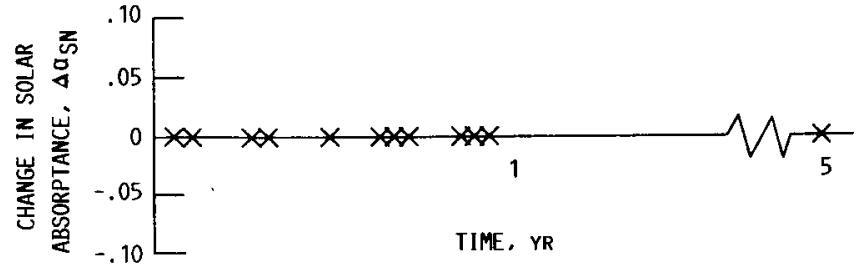

FIGURE 11.

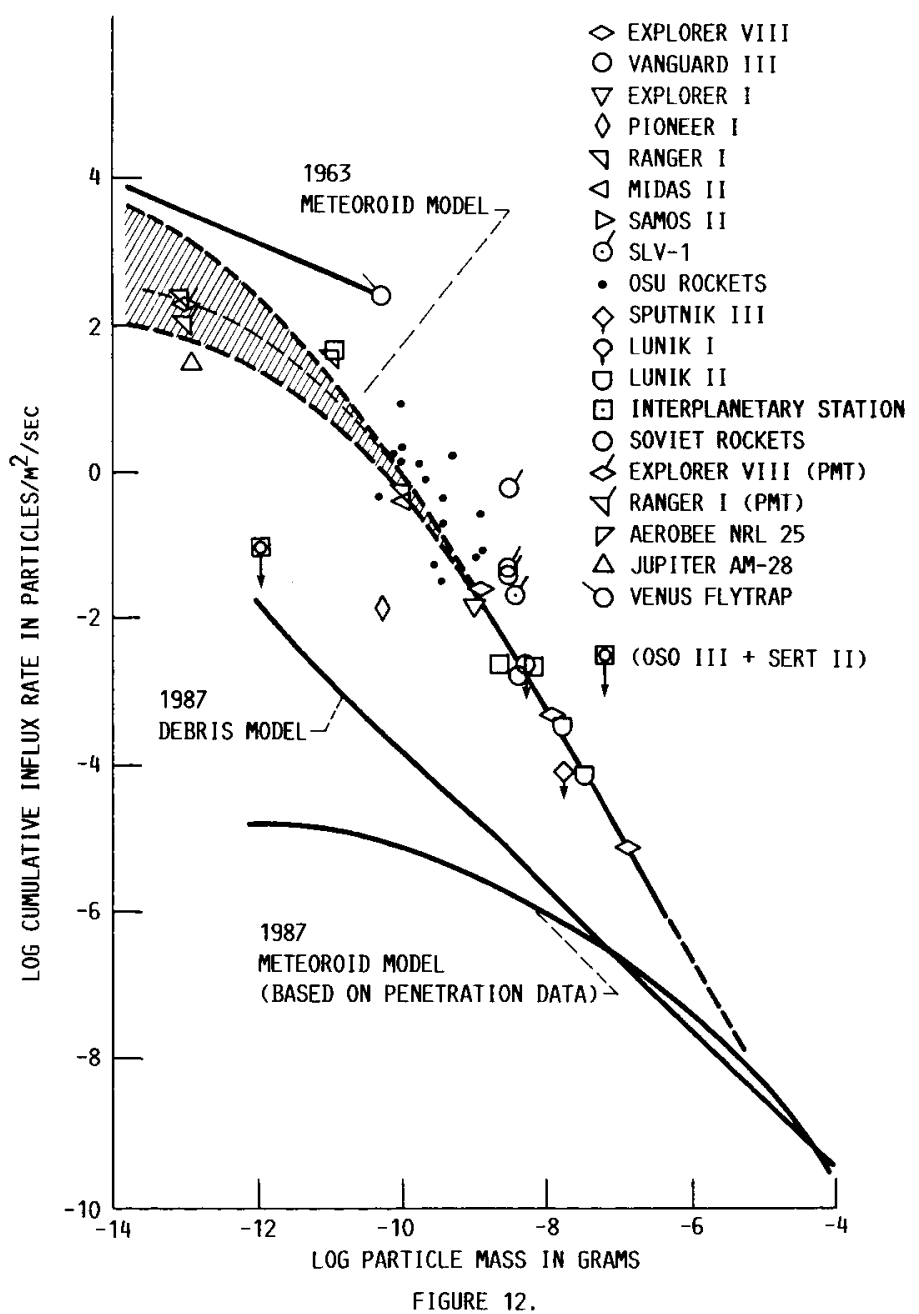




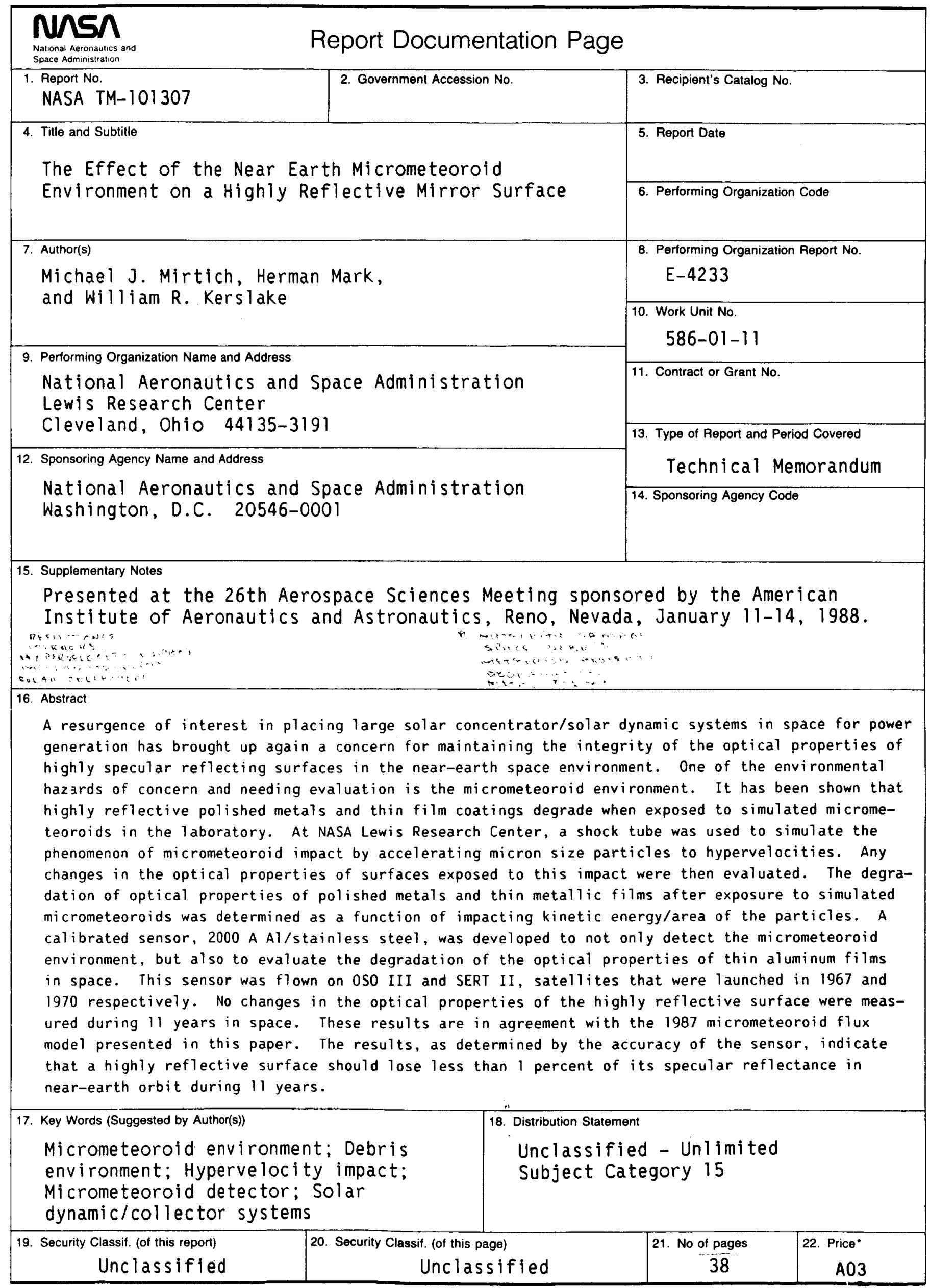

NASA FORM 1626 OCT $86 \quad$ *For sale by the National Technical Information Service, Springfield, Virginia 22161 